\title{
Myofascial Foot Pain Following Uneventful Epidural Analgesia for Labor and Delivery
}

\author{
Badie S. Mansour*, Gretchen M. Wienecke, Jorge A. Cure, Jeremy T. Almon, Alberto J. de Armendi
}

University of Oklahoma Health Sciences Center, Department of Anesthesiology and Pain Medicine, Oklahoma City, USA. Email: *Badie-Mansour@ouhsc.edu

Received October $18^{\text {th }}, 2011$; revised November $25^{\text {th }}, 2011$; accepted December $7^{\text {th }}, 2012$

\begin{abstract}
Following an uneventful delivery under epidural analgesia, a 17-year-old female patient was referred to the pain clinic because of numbness and pain of the left big toe for $2 \frac{1}{2}$ Months. An orthopedic consultation had ruled out foot injury and concluded that the pain was radicular and secondary to nerve damage from the epidural analgesia. A pain clinic evaluation made the diagnosis of myofascial pain which was successfully treated with a trigger point block using normal saline.
\end{abstract}

Keywords: Myofascial Pain; Trigger Point; Epidural Analgesia; Delivery in Adolescent; Local Infiltration; Chronic Foot Pain

\section{Introduction}

Only two obstetrical post-partum cases with myofascial pain have been reported in the literature (after Ovid and PubMed searches). Tsen and Camann report on one post-partum patient with lumbar myofascial pain [1], and Hubbell and Thomas reviewed four patients with postpartum cervical myofascial pain [2]. We report an unusual case of foot myofascial pain in a 17 year-old patient following an uneventful labor and delivery under epidural analgesia.

\section{Case Report}

A 17-year old girl, healthy with no known allergies or previous health problems, presented to the pain clinic with a chief complaint of pain and numbness of the left big toe for $2 \frac{1}{2}$ months. Her past medical history revealed that her pregnancy was uneventful and she delivered her first baby $2 \frac{1}{2}$ months ago. During her labor she received a continuous lumbar epidural infusion of ropivacaine $0.2 \%$ at $10 \mathrm{ml}$ per hour for analgesia. The lumbar epidural catheter was placed without difficulty. She described her labor analgesia as good. And she did not have any pain during labor or delivery. She delivered vaginally a full term healthy infant vaginally and without any

\footnotetext{
${ }^{*}$ Corresponding author.
}

difficulty. Following delivery the epidural catheter was removed with the catheter tip intact. The duration of the epidural catheter placement was less than 24 hours. During the duration of the epidural analgesia she had numbness of both lower legs. However, as she was recovering from the effect of the local anesthetic, she noted numbness in her left lower limb for $3 \frac{1}{2}$ days. The patient was not clear if the numbness involved the entire limb, but at least her foot and part of her left limb was numb. After $3 \frac{1}{2}$ days the sensation returned to her left lower limb except for numbness of the left big toe. She also noticed pain in her left big toe in spite of the persistent numbness. The pain intensified during the next 3 weeks, and became continuous. She was not able to give a number on the Visual Analogue Scale (VAS), but she said the pain was severe enough that it interfered with her walking. She described her pain as deep, aching and continuous. It increased as the day progressed and the pain was especially intense at the end of the day. Pain medication, mainly hydrocodone, helped a little but not enough to make her comfortable. Sitting and lying down did not relieve her pain. She lived with her mother, who took care of her and her baby. Her mother indicated that her daughter had difficulty going to the school, and she could not finish the school day because the pain became intolerable.

Her primary physician referred her to an orthopedic 
surgeon, who examined her and obtained an x-ray of the left foot and ruled out any fracture. A diagnosis of nerve root damage secondary to the epidural was made by the surgeon and she was referred to our pain clinic. Following the history, the physical examination revealed that she had decreased sensation in the L5 nerve root distribution and her left big toe was noted to be hyperalgesic and had noticeable decreased temperature by touch compared to the opposite site. Temperatures of both sides were not measured. Mild swelling of dorsum of the left foot between the $1^{\text {st }}$ and $2^{\text {nd }}$ metatarsal without skin discoloration was also noted. A straight leg raising test was negative bilaterally and no motor deficit or dysfunction of either lower extremity was noted. Tenderness of the flexor hallucis brevis muscle was noted. See Figure 1.

Applying pressure on the trigger point of the hallucisbrevis muscle intensified the aching pain of the great toe. A diagnosis of myofascial pain was made and the initial treatment consisted of a trigger point block of the flexor hallucisbrevis muscle with normal saline $0.5 \mathrm{ml}$. Normal saline was chosen instead of a local anesthetic in order to avoid pain relief and numbness due to the effect of the local anesthetic. After the block, she reported that the pain had markedly decreased and the numbness had disappeared. She was able to walk without a limp. One week later, at her follow up visit, the patient stated that she had improved considerably. She was able to function, walk and go to school. She still had mild to moderate pain of the dorsum of her left foot. She still had no pain of left big toe. On exam, she had mild swelling and tenderness of the dorsum of her left foot. The tenderness was diffuse and no trigger point was found. She was treated with a local infiltration of a $3 \mathrm{ml}$ mixture of bupivacaine $0.25 \%$ and of methylprednisolone $4 \mathrm{mg} / \mathrm{ml}$. She reported resolution of the pain and tenderness. She cancelled her follow up appointment two weeks later because of complete recovery.

\section{Discussion}

Myofascial pain syndrome (MPS) is a common cause of acute and chronic pain. It is common after injury, resulting in so called soft tissue pain. The pain can be mild, moderate or debilitating and disabling. Pain is usually aching in character and constant. However, the hallmark of MPS is finding a trigger point. The trigger point can be active and accompanied by symptoms or latent and has no symptoms.

The active trigger point's physical features are:

1) Exquisite tenderness in a taut muscle band

2) Referred pain elicited or exacerbated by stimulation of the trigger point.

3) A local twitch or contraction of the taut band elicited by mechanical stimulation of the trigger point.

4) Restricted range of motion of the affected area [3].

We present a case report of persistent pain and numb- ness of the left great toe after discontinuation of a continuous labor epidural anesthesia. Our patient continued to have numbness of the left leg for $3 \frac{1}{2}$ days after discontinuation of the epidural infusion with ropivacaine $0.2 \%$. However over time she recovered from the numbness. A possible explanation is that a continuous infusion of the ropivacaine close to the nerve root may have caused a reversible prolonged effect on the nerve root.

It is possible that during this time of $3 \frac{1}{2}$ days, the numbness of her left leg may have led to trauma to the soft tissue of the left foot, which was unnoticed by the patient.

Our patient first noticed the pain after recovering from the numbness of her leg. The pain gradually increased and became severe enough to interfere with her daily activity and ability to function in school. Also she noticed a numb feeling limited to the left big toe. A bone fracture was ruled out with an x-ray [4]. Complex regional pain syndrome was not supported with clinical signs. However another possible diagnosis was nerve root or peripheral nerve injury. But our patient had no clinical findings to support this diagnosis.

We elected to rule out myofascial pain syndrome, before proceeding with nerve conduction testing. Trigger
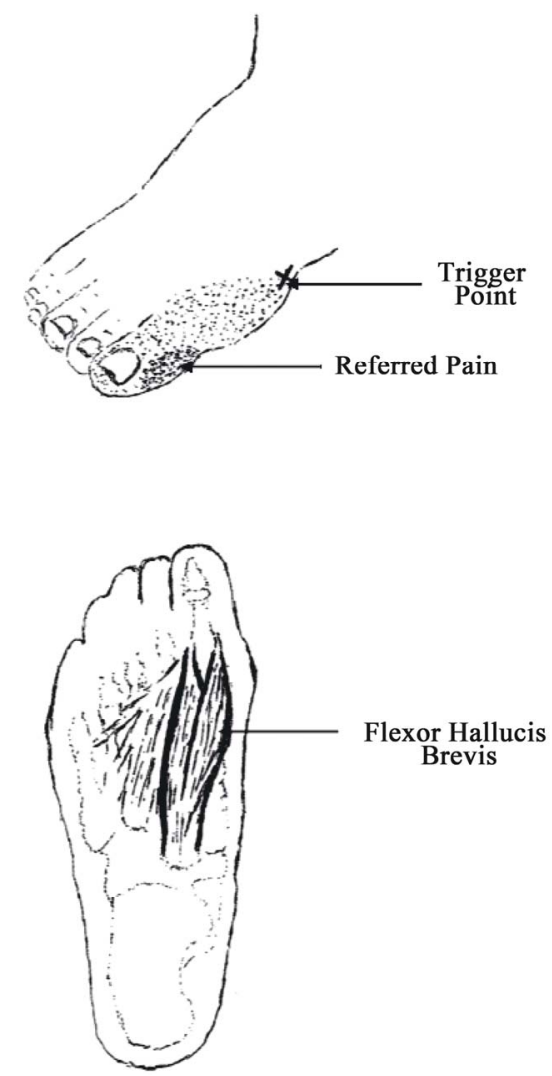

Figure 1. Flexor hallucis brevis. 
combination of both or normal saline [5,6]. We elected to use normal saline to avoid any confusion about if the pain relief was due to nerve block vs. trigger point inactivation of the left flexor hallucis brevis, immediate relief of the pain following injecting the trigger point is proof that the pain is due to MPS. Not only did she have pain relief, but she also recovered from the numb feeling of the left big toe.

The pain of the dorsum of the left foot was not due to MPS, but rather due to mild tendinitis and resolved after steroid and local anesthetic infiltration.

Lawrence C. Tsen M.D and William R. Camann, M.D reported pain relief after trigger point injection for Myofascial pain during epidural analgesic for labor in a patient that presented in active labor [1]. She developed low back pain during her pregnancy without radiculopathy. She continued to have low back pain in spite of successful epidural analgesia and solid bilateral $\mathrm{T} 10$ block. Despite this she continued to have discomfort in her low back. Upon examination and palpation of the right paraspinous muscle, two discrete tender points at L 4.5. After injecting the trigger points with Marcain $0.25 \%$ the back pain improved [1]. In our patient, the Myofascial pain developed during labor or after delivery. She responded well after trigger point injection with normal saline.

MPS is a common cause of chronic pain [6]. We presented this unusual case of MPS that affected a very y- oung obstetric patient obstetric and very young patient, which completely resolved after treatment with a trigger point block. Also we showed that using normal saline for the trigger point block can be as effective as local anesthetic. Please see Figure 1.

\section{REFERENCES}

[1] L. C. Tsen and W. R. Camann, “Trigger Point Injections for Myofascial Pain During Epidural Analgesia for Labor,” Regional Anesthesia, Vol. 22, No. 5, 1997, pp. 466468. doi:10.1016/S1098-7339(97)80035-1

[2] S. L. Hubbell and M. Thomas, "Postpartum Cervical Myofascial Pain Syndrome: Review of Four Patients," Obstetrics and Gynecology, Vol. 65, Suppl. 3, 1985, pp. 56S-57S

[3] R. D..Gerwom, "Myofascial Pain Syndromes from Trigger Points," Current Pain and Headache Reports, Vol. 3, No. 2, 1999, pp. 153-159.

[4] M. A. Joong and G. Y. El-Khoury, "Radiologic Evaluation of Chronic Foot Pain,” American Family Physician, Vol. 76, No. 7, 2007, pp. 975-983.

[5] P. P. Raj, “Myofascial Trigger Point Injection,” In: P. P. Raj, Ed., Practical Management of Pain, Year Book Medical Publishers, Chicago, 1986, pp. 569-577.

[6] Travell and Simons, "Myofascial Pain and Dysfunction. The Trigger Point Manual, the Lower Extremities,” 2nd Edition, Williams \& Wilkins, Baltimore, 1998, p.526. 